\title{
KESULITAN SISWA GAYA BELAJAR KINESTETIK DALAM MENYELESAIKAN SOAL HOTS
}

\author{
Mei Wijayadi ${ }^{1}$, Prasetyo B. Darmono ${ }^{2}$, Nila Kurniasih ${ }^{3}$ \\ Program Studi Pendidikan Matematika, Universitas Muhammadiyah Purworejo 1,2,3 \\ Email: meiwijayadi1@gmail.com
}

\begin{abstract}
Abstrak
Soal HOTS merupakan soal dengan tingkat kesulitan tinggi, sehingga diperlukan kemampuan yang tinggi juga dalam penyelesaiannya. Oleh sebab itu, terdapat siswa yang kesulitan dalam penyelesaian soal HOTS. Kesulitan yang dialami siswa dalam menyelesaikan soal tersebut beragam. Kesulitan tersebut dikarenakan oleh banyak faktor salah satunya gaya belajar siswa. Gaya belajar siswa dikategorikan menjadi tiga jenis, yaitu kinestetik, auditorial dan visual. Penelitian ini membahas tentang gaya belajar kinestetik. Subjek penelitian ini yaitu siswa kelas X MIPA 1 dan X MIPA 3. Metode penelitian kualitatif deskriptif digunakan dalam penelitian ini, sehingga tujuan penelitiannya yaitu mendeskripsikan kesulitan siswa gaya belajar kinestetik dalam menyelesaikan soal HOTS. Pengumpulan data menggunakan angket, tes, wawancara, dan catatan lapangan. Data dianalisis menggunakan teknik analisis data Miles and Hubberman, yaitu data reduction, data display dan conclussion drawing. Hasil penelitian ini yaitu siswa gaya belajar kinestetik mengalami kesulitan pada tahap memahami konsep untuk soal dengan tingkat C4. Kesulitan tersebut disebabkan siswa kurang teliti dalam mengerjakan soal.
\end{abstract}

Kata Kunci : Kesulitan Siswa, Kinestetik, HOTS, Gaya Belajar

\begin{abstract}
HOTS problem is a problem with high difficulties level, so that advanced proficiency are required to solve those problems. However, there are students who get difficulties in solving HOTS problems. The difficulties of students in solving problems are varied. The difficulties are caused by many factors, one of them is student learning style. Student learning styles are categorized into three types, namely kinesthetic, auditorial and visual. This research was focused on kinesthetic learning style. This research used descriptive qualitative method, so it was purposed to describe the kinestethic students difficulties in solving HOTS problems. Data were collected by quistionnarie, test and field notes. Data were analized by Miles and Hubberman analysis technique, there were data reduction, data display and conclussions drawing. The research result was that kinesthetic student get difficulties on in understanding concept level for C4 level problem. The factor of students' difficulties is that the students are not careful in solving problem.
\end{abstract}

Key Words : Student Difficulties, Kinesthetic, HOTS, Learning Style

\section{PENDAHULUAN}

Di zaman seperti sekarang ini dibutuhkan siswa-siswa yang kreatif dan kritis guna meningkatkan pendidikan Indonesia. Kemampuan siswa tersebut bisa diwujudkan dengan pemberian soal-soal tingkat tinggi pada siswa. Soal-soal ini biasanya disebut soal HOTS (Higher Order Thinking Skills). Kemampuan-kemampuan siswa tersebut untuk membekali dan menciptakan lulusan yang siap dalam menghadapi kehidupan mendatang. Selain itu, karena matematika sangat penting bagi kehidupan siswa. Hal serupa juga diungkapkan melalui hasil penelitian, yaitu matematika bersifat mendasar, sehingga penting bagi kehidupan [1].

Pentingnya matematika ditandai dengan banyaknya penerapan matematika dalam kehidupan. Salah satu cara meningkatkan kemampuan matematika siswa yaitu dengan pemberian soal HOTS. Namun, pemberian soal HOTS kadangkala menambah kendala dalam pembelajaran karena siswa mengalami kesulitan dalam menyelesaikannya. Hal serupa juga diungkapkan dalam hasil penelitian, yaitu 
siswa masih kesulitan dalam menyelesaikan soal-soal HOTS [2]. Sehingga perlu adanya penelitian lebih lanjut tentang kesulitan siswa dalam menyelesaikan soal HOTS.

Penelitian ini bertujuan untuk mengetahu kesulitan menyelesaikan soal HOTS dalam matematika ditinjau dari gaya belajar kinestetik, dengan demikian dapat diberikan masukan untuk meminimalisir kesulitan yang dialami siswa. Meskipun telah ada penelitian tentang kesulitan siswa, namun dalam penelitian ini dibahas jika ditinjau dari gaya belajar kinestetik. "HOTS adalah proses berpikir yang mengharuskan siswa untuk memanipulasi informasi dan ide-ide dalam cara tertentu yang memberi mereka pengertian dan implikasi baru” [3].

Menurut King, dkk., HOTS memuat kemampuan berpikir kritis, logis, reflektif, metakognitif, dan kreatif [4]. Tidak semua soal bisa dikategorikan sebagai soal HOTS. Sehingga dari beberapa pengertian yang telah disampaikan, dapat disimpulkan bahwa soal HOTS adalah soal-soal yang penyelesaiannya memerlukan berpikir kritis kreatif dan berpikir tingkat tinggi lainnya. Karena soal HOTS memiliki karakteristik.

Berikut dijelaskan karakteristik soal HOTS [5]:

1. Mengukur kemampuan berpikir tingkat tinggi dan meminimalkan aspek ingatan siswa atau pengetahuan.

2. Berbasis permasalahan kontekstual.

3. Stimulus menarik.

4. Tidak monoton.

Menurut Anderson \& Krathwohl [6], indikator untuk mengukur kemampuan berpikir tingkat tinggi (HOTS) sebagai berikut.

Tabel 1. Indikator HOTS

\begin{tabular}{|c|c|c|}
\hline No. & $\begin{array}{l}\text { Tingkat } \\
\text { kognitif }\end{array}$ & Indikator \\
\hline 1. & $\begin{array}{l}\text { Analysis } \\
\text { (C1) }\end{array}$ & \begin{tabular}{ll} 
a. & \multicolumn{3}{l}{ Menganalisis informasi yang telah diperoleh. } \\
b. Mengidentifikasi faktor-faktor & yang \\
menyebabkan dan mengetahui akibat suatu \\
rumus digunakan.
\end{tabular} \\
\hline & & $\begin{array}{l}\text { c. Merumuskan pertanyaan-pertanyaan terkait } \\
\text { informasi yang diperoleh. }\end{array}$ \\
\hline 2. & $\begin{array}{l}\text { Evaluate } \\
\text { (C2) }\end{array}$ & $\begin{array}{l}\text { a. Memberi penilaian suatu gagasan dengan } \\
\text { kriteria. }\end{array}$ \\
\hline & & $\begin{array}{l}\text { b. Membuat hipotesis tentang gagasan yang } \\
\text { sudah dinilai. } \\
\text { c. Memberikan penerimaan gagasan atau } \\
\text { penolakan gagasan dengan pengujian. }\end{array}$ \\
\hline 3. & $\begin{array}{l}\text { Creat } \\
\text { (C3) }\end{array}$ & $\begin{array}{l}\text { a. Menggeneralisasi gagasan. } \\
\text { b. Merancang cara penyelesaian masalah. } \\
\text { c. Mengorganisasi bagian-bagian kecil menjadi } \\
\text { struktur baru. }\end{array}$ \\
\hline
\end{tabular}

Cooney menyatakan bahwa kesulitan siswa dibedakan menjadi tiga jenis, yaitu: kesulitan dalam memahami konsep, kesulitan dalam menggunakan prinsip dan kesulitan dalam menyelesaikan masalah verbal [7]. Siswa bisa mengalami kesulitan pada gabungan dari beberapa jenis yang telah disebutkan, namun ada pula siswa yang hanya mengalami salah satu kesulitan dari ketiga jenis tersebut. Indikator kesulitan siswa dipaparkan dalam Tabel berikut: 
Tabel 2. Indikator Kesulitan Siswa

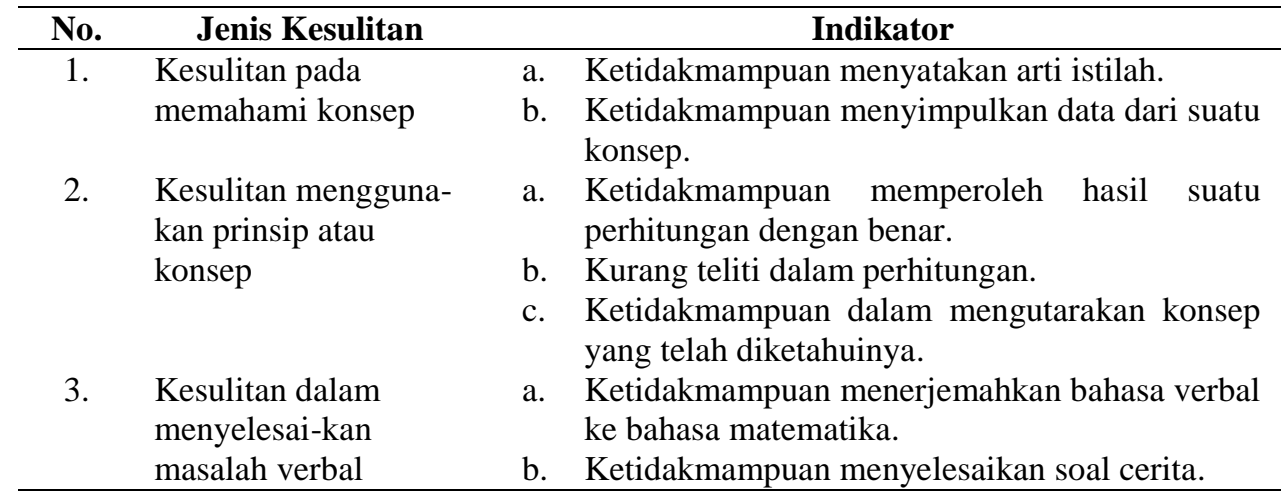

Terdapat faktor-faktor penyebab kesulitan siswa, salah satu faktor itu adalah gaya belajar siswa. Hal ini disebutkan pula dalam hasil penelitian yaitu gaya belajar siswa mempengaruhi prestasi belajar, prestasi belajar mempengaruhi bagaimana kesulitan siswa yang dialami siswa [8]. Gaya belajar, merupakan kebiasaan seseorang dalam proses belajar [9]. Selanjutnya B. DePorter dan H. Mike membagi jenis-jenis gaya belajar, yaitu kinestetik, auditorial, dan visual [10]. Penelitian ini hanya membahas tentang gaya belajar kinestetik. Gaya belajar tersebut dipilih karena dalam lapangan penelitian, terdapat lebih banyak siswa kinestetik dari pada siswa auditorial dan visual. Berikut indikator jenis gaya belajar auditorial:

\section{Tabel 3. Indikator Gaya Belajar Kinestetik}

\begin{tabular}{lll}
\hline Gaya Belajar & & \multicolumn{1}{c}{ Indikator } \\
\hline & 1. & Bicara dengan perlahan. \\
\multirow{3}{*}{ Kinestetik } & 2. & Banyak bergerak. \\
& 3. & Belajar dengan praktik atau gerakan. \\
& 5. & Menghafal dengan melihat kemudian berjalan-jalan. \\
& 6. & Banyak menggunakan isyarat tubuh. \\
\hline
\end{tabular}

\section{METODE}

Dalam penelitian ini menggunakan metode penelitian kualitatif deskriptif. Penelitian ini bertujuan untuk mendeskripsikan kesulitan siswa gaya belajar kinestetik dalam menyelesaikan soal HOTS. Penelitian ini diambil 2 subjek dari siswa SMA kelas X MIPA 1 dan 3 di Kabupaten Purworejo, pengambilan subjek dilakukan pada April 2021. Subjek dipilih berdasarkan pertimbangan guru dan kuisioner tentang gaya belajar. Instrumen utama dari penelitian ini yaitu peneliti sendiri, hal tersebut sesuai dengan pendapat yaitu penelitian kualitatif menjadikan peneliti sebagai instrumen utama [11].
Peneliti menggunakan kuisioner gaya belajar sebagai pengklasifikasian calon subjek penelitian, kemudian dilakukan tes soal HOTS untuk mengukur tingkat kesulitan siswa serta membuat catatan lapangan sebagai pendukung, dan wawancara untuk menguatkan data hasil penelitian.

Indikator wawancara yang digunakan sesuai dengan tabel indikator gaya belajar. Teknik analisis data yang digunakan yaitu teknik analisis data Miles \& Huberman, yaitu data reduction, data display dan conlusion drawing [12]. 


\section{HASIL DAN PEMBAHASAN}

Langkah berikutnya, setelah dilakukan pengumpulan data, kemudian dilakaukan pembahasan data. Berikut hasil dan pembahasan data penelitian.

\section{Subjek $\mathbf{K}_{1}$}

Berdasarkan hasil pemberian kuisioner pada 27 Januari 2021, $\mathrm{K}_{1}$ merupakan subjek dengan gaya belajar kinestetik. Untuk memastikan bahwa siswa tersebut memiliki gaya belajar kinestetik peneliti melaksanakan observasi sehingga diperoleh catatan lapangan, peneliti juga melakukan wawancara pada 22 Februari 2021 setelah $\mathrm{K}_{1}$ melaksanakan pembelajaran. Selanjutnya, setelah diperoleh bukti yang valid, diputuskan $\mathrm{K}_{1}$ sebagai subjek penelitian. Selanjutnya $\mathrm{K}_{1}$ diberi tes dengan 3 soal tingkat HOTS pada tanggal 27 Februari 2021. Tes diberikan setelah pembelajaran selesai, agar tidak mengganggu kegiatan pembelajarannya. Berikut hasil pengerjaan tes $\mathrm{K}_{1}$ :

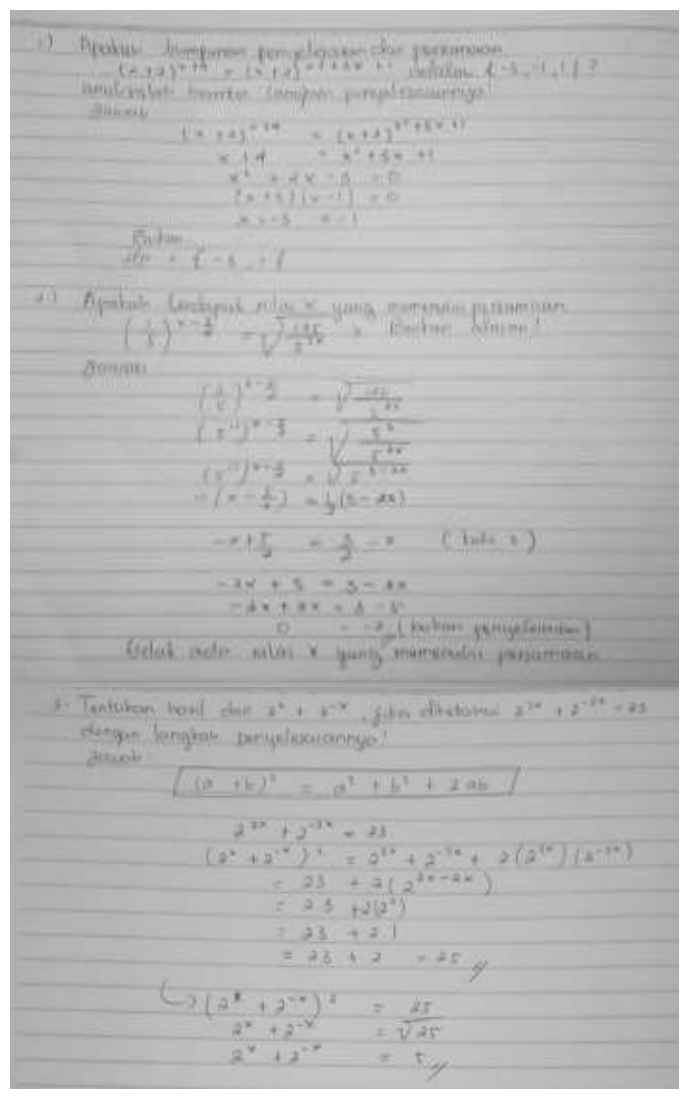

Gambar 1. Hasil Pengerjaan $K_{1}$
Terlihat dari hasil pengerjaan $\mathrm{K}_{1}$ dapat mengerjakan semua soal sampai selesai. Setelah tes, kemudian dilakukan wawancara tentang jawaban siswa tersebut. Berdasarkan hasil pengerjaan, hasil wawancara dan catatan lapangan, $\mathrm{K}_{1}$ tidak mengalami kesulitan dalam menyelesaikan ketiga soal tersebut yang merupakan soal dengan tingkat $\mathrm{C} 4, \mathrm{C} 5$ dan C6 secara berturut-turut. Namun pada nomor $1, \mathrm{~K}_{1}$ kurang teliti dalam menyelesaikan soal, masih terdapat jawaban yang kurang lengkap.

$\mathrm{K}_{1}$ tidak merasakan kesulitan karena sudah pernah menemui soal serupa. Kesulitan yang dialami $\mathrm{K}_{1}$ pada soal nomor 1 tergolong kesulitan pada tahap memahami konsep. Hal ini dapat dilihat dari ketidakmampuan dalam mengingat satu atau lebih kondisi yang dapat dikaitkan dengan konsep. Sehingga $K_{1}$ juga tidak dapat menggunakan konsep yang harus digunakan dalam menyelesaikan soal tersebut.

Selain jenis kesulitan yang dialami, berdasarkan hasil pengerjaannya, $\mathrm{K}_{1}$ tidak memenuhi indikator secara keseluruhan dalam penyelesaian soal HOTS. Berikut rinciannya:

1. Penyelesaian soal nomor $1, \mathrm{~K}_{1}$ hanya memenuhi beberapa indikator, yaitu mengetahui akibat dari sebuah skenario atau rumus yang digunakan yang berupa menentukan faktor dari persamaan kuadrat yang dihasilkan dari persamaan pangkat dan analisis informasi yang diperoleh berupa menuliskan informasi dari soal dan memerumuskan pertanyaan terkait informasi yang didapat berupa pemberian kesimpulan.

2. Penyelesaian soal nomor $2, \mathrm{~K}_{1}$ telah memenuhi semua indikator.

3. Penyelesaian soal nomor $3, \mathrm{~K}_{1}$ telah memenuhi semua indikator. 


\section{Subjek $\mathbf{K}_{2}$}

Berdasarkan hasil pemberian kuisioner pada 27 Januari 2021, $\mathrm{K}_{2}$ adalah subjek dengan gaya belajar kinestetik. Peneliti melaksanakan observasi sehingga diperoleh catatan lapangan, peneliti juga melakukan wawancara pada 22 Februari 2021 setelah $\mathrm{K}_{2} \quad$ melaksanakan pembelajaran untuk memastikan bahwa siswa tersebut memiliki gaya belajar kinestetik. Kemudian diputuskan $\mathrm{K}_{2}$ sebagai subjek penelitian setelah memperoleh bukti yang valid. Selanjutnya $\mathrm{K}_{2}$ diberi tes dengan 3 soal tingkat HOTS pada tanggal 27 Februari 2021. Tes diberikan setelah pembelajaran selesai, agar tidak mengganggu kegiatan pembelajarannya. Berikut hasil pengerjaan tes $\mathrm{K}_{2}$ :

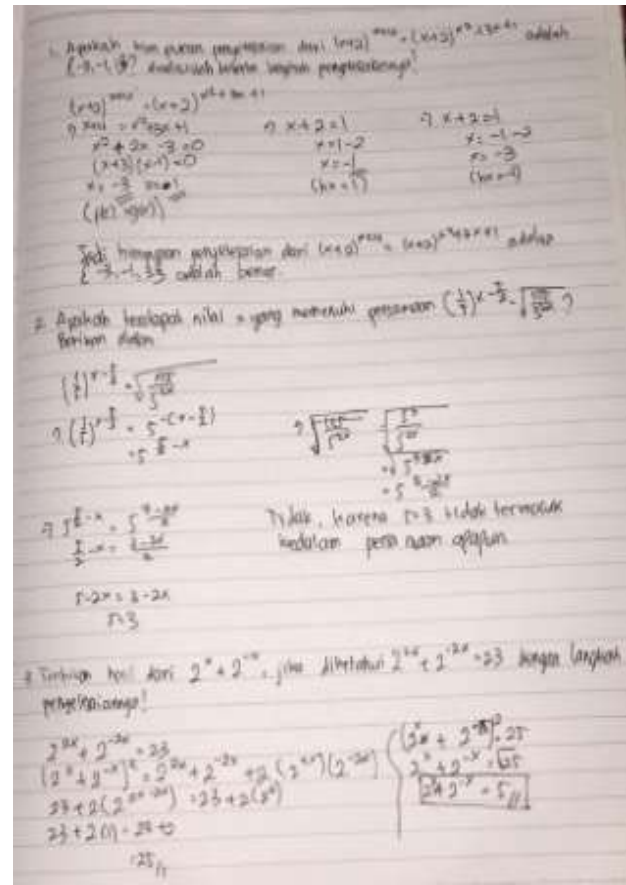

Gambar 2. Hasil Pengerjaan $K_{2}$

Terlihat dari hasil pengerjaan $\mathrm{K}_{2}$ dapat mengerjakan semua soal sampai selesai. Setelah tes dilakukan, dilakukan wawancara tentang jawaban siswa tersebut. Berdasarkan hasil pengerjaan siswa, wawancara dan catatan lapangan, $\mathrm{K}_{2}$ tidak mengalami kesulitan dalam menyelesaikan ketiga soal tersebut yang merupakan soal dengan tingkat $\mathrm{C} 4, \mathrm{C} 5$ dan $\mathrm{C} 6$ secara berturut-turut. Namun pada nomor $1, \mathrm{~K}_{2}$ kurang teliti dalam menyelesaikan soal, masih terdapat jawaban yang kurang lengkap. K2 tidak merasakan kesulitan karena sudah pernah menemui soal serupa. Kesulitan yang dialami K2 pada soal nomor 1 tergolong kesulitan pada tahap memahami konsep. Hal ini dapat dilihat dari ketidakmampuan dalam mengingat satu atau lebih kondisi yang dapat dikaitkan dengan konsep. Sehingga K2 juga tidak dapat menggunakan konsep yang harus digunakan dalam menyelesaikan soal tersebut.

Selain jenis kesulitan yang dialami, berdasarkan hasil pengerjaannya, $\mathrm{K}_{2}$ tidak memenuhi indikator secara keseluruhan dalam penyelesaian soal HOTS. Berikut rinciannya:

1. Penyelesaian soal nomor $1, \mathrm{~K}_{2}$ hanya memenuhi beberapa indikator, yaitu mengetahui akibat dari sebuah skenario atau rumus yang digunakan yang berupa menentukan faktor dari persamaan kuadrat yang dihasilkan dari persamaan pangkat dan analisis informasi yang diperoleh berupa menuliskan informasi dari soal dan memerumuskan pertanyaan terkait informasi yang didapat berupa pemberian kesimpulan.

2. Penyelesaian soal nomor $2, \mathrm{~K}_{2}$ telah memenuhi semua indikator.

3. Penyelesaian soal nomor $3, \mathrm{~K}_{2}$ telah memenuhi semua indikator.

Berdasarkan data yang dijelaskan di atas, maka dapat disimpulkan bahwa siswa yang memiliki gaya belajar kinestetik $\left(\mathrm{K}_{1}\right.$ dan $\mathrm{K}_{2}$ ) mengalami kesulitan pada tahap memahami konsep untuk soal dengan tingkat $\mathrm{C} 4$ disebabkan siswa kurang teliti dengan penyelesaian soal tersebut. Hal ini mengakibatkan tidak tercapainya indikator penyelesaian soal HOTS secara maksimal. Hasil penelitian memaparkan bahwa siswa 
dengan gaya belajar kinestetik mengalami kesulitan yang tergolong sedikit sehingga hasil belajarnya tinggi, hal ini sesuai dengan hasil penelitian [13] bahwa siswa dengan gaya belajar kinestetik mendapatkan nilai rata-rata hasil belajar lebih tinggi dari pada nilai rata-rata hasil belajar siswa dengan gaya lainnya.

\section{SIMPULAN}

Berdasarkan analisis data yang diperoleh, siswa gaya belajar kinestetik mengalami kesulitan pada tahap memahami konsep untuk soal dengan tingkat $\mathrm{C} 4$. Kesulitan tersebut disebabkan siswa tidak terbiasa dan kurang teliti dalam mengerjakan soal. Kesulitan tersebut menyebabkan indikator penyelesaian soal HOTS tidak terpenuhi.

\section{DAFTAR PUSTAKA}

[1] Ernawati dan S. Sutiarso, "Analisis Kesulitan Menyelesaikan Soal Matematika Kategori Higher Order Thinking Skills," J. Penelit. Pembelajaran Mat., vol. 13, pp. 178195, 2020.

[2] S. Hadi, H. Retnawati, S. Munadi, E. Apino, and N. F. Wulandari, "THE DIFFICULTIES OF HIGH SCHOOL STUDENTS IN SOLVING HIGHER-ORDER," PROBLEMS OF EDUCATION IN THE 21st CENTURY, vol. 76, no. 4, 2018.

[3] A. W. Gunawan, Genius Learning Strategy: Petunjuk Praktis untuk Menerapkan Accelerated Learning. Jakarta: Gramedia Pustaka Utama, 2012.

[4] A. S. Shidiq, M. Masykuri, dan E. Susanti, "Analisis Higher Order Thinking Skills (HOTS) Menggunakan Instrumen Two-Tier Multiple Choice pada Materi Kelarutan dan Hasil Kali Kelarutan untuk Siswa Kelas XI SMA N 1 Surakarta," Pros. Semin. Nas. Pendidik. Sains, no. November, pp.
2015-159, 2015.

[5] P. P. Astutik, HOTS Berbasis PPK dalam Pembelajaran Tematik. Surabaya: Pustaka Media Guru, 2018.

[6] D. Fallentza, R. Setyawati, dan N. Rahmawati, "Analisis kemampuan berpikir tingkat tinggi siswa SMP dalam menyelesaikan soal matematika tipe HOTS," Univ. Pgri Semarang, vol. 21, no. 1, pp. 118119, 2021.

[7] U. Dwidarti, H. L. Mampouw, dan D. Setyadi, "Analisis Kesulitan Siswa dalam Menyelesaikan Soal Cerita pada Materi Himpunan," $J$. Cendekia J. Pendidik. Mat., vol. 3, no. 2, pp. 315-322, 2019, doi: 10.31004/cendekia.v3i2.110.

[8] M. S. Rambe dan N. Yarni, "Pengaruh Gaya Belajar Visual, Auditorial dan Kinestetik terhadap Prestasi Belajar Siswa SMA Dian Andalas Padang," Jurnal JRPP, vol. 2, no. 2, pp. 291-296, 2019.

[9] S. Jaleel and M. T. Anne, Learning Styles: Theories and Implications for Teaching Learning. USA: Horizon Research Publishing, 2019.

[10] B. DePorter and H. Mike, Quantum Learning: Membiasakan Belajar Nyaman dan Menyenangkan. Bandung: Kafia, 2013.

[11] J. W. Creswell, Research Design: Pendekatan Metode Kualitatif, Kuantitatif, dan Campuran. Yogyakarta: Pustaka Pelajar, 2016.

[12] Sugiyono, Metode Penelitian Pendidikan: Pendekatan Kuantitatif, Kualitatif, dan $R \& D$. Bandung: Alfabeta, 2015.

[13] L. Hartati, "Pengaruh Gaya Belajar dan Sikap Siswa pada Pelajaran Matematika terhadap Hasil Belajar Matematika," FORMATIF: Jurnal Ilmiah Pendidikan MIPA, vol. 3, no. 3, pp. 224-235, 2013. 